\title{
A INCONSTITUCIONALIDADE DA PROPOSTA DE RETORNO À INCAPACIDADE DA PESSOA COM DEFICIÊNCIA (PLS 757/2015) FRENTE À CONVENÇÃO DE NOVA IORQUE
}

\author{
THE INCONSTITUTIONALITY OF THE PROPOSAL TO RETURN TO THE \\ DISABILITY OF PERSONS WITH DISABILITIES (PLS 757/2015) IN THE \\ FRAMEWORK OF THE NEW YORK CONVENTION
}

\section{LA INCONSTITUCIONALIDAD DE LA PROPUESTA DE RETORNO A LA INCAPACIDAD DE LA PERSONA CON DISCAPACIDAD (PLS 757/2015) FRENTE A LA CONVENCIÓN DE NUEVA YORK}

\author{
ALFREDO COPETTI NETO \\ http://lattes.cnpq.br/6336504347602827 / https://orcid.org/0000-0002-6997-9603 / alfredocopetti@yahoo.com \\ Universidade Estadual do Oeste do Paraná / Faculdade Guanamb \\ Cascavel, Paraná, Brasil. / Guanambi, Bahia, Brasil
}

ALEXANDRE BARBOSA DA SILVA http://lattes.cnpq.br/9001465175088901 / https://orcid.org/0000-0001-5971-8824 / alexandre@univel.br Centro Universitário de Cascavel Cascavel, Paraná, Brasil.

\begin{abstract}
RESUMO
A presente pesquisa tem o intuito de descrever o patamar em que se encontra, no direito pátrio, a proteção das pessoas com deficiência, bem como analisar a questão do retorno da incapacidade da pessoa com deficiência. Para tanto, aborda-se a Convenção da ONU sobre o tema, a sua aprovação no Brasil como Emenda Constitucional e a construção da legislação infraconstitucional atinente. Assim, há a tentativa de ofertar fundamentos que permitam reconhecer na pessoa com deficiência sua absoluta capacidade, sem olvidar da merecida proteção, por conta da sua diferença, que continua a existir no direito pátrio, mas, doravante, sob o viés constitucional. A perspectiva, portanto, é de dupla face: de fundamentar, com base nos direitos fundamentais, a capacidade plena da pessoa com deficiência; de reconhecer a consequente inconstitucionalidade de eventual norma que negue essa capacidade.
\end{abstract}

Palavras-chave: Convenção de Nova Iorque; Pessoas Com Deficiência; Capacidade; Direitos Fundamentais.

\section{ABSTRACT}

The purpose of the text is to describe the level of protection of persons with disabilities in the country's law, so as the issue of the disability return. To do so, it addresses the UN Convention on the subject, its adoption in Brazil as Constitutional Amendment and the construction of relevant infraconstitutional legislation. Thus, there is the attempt to offer foundations that allow to recognize in the person with disabilities their absolute capacity, without forgetting the deserved protection, because of their difference, which continues to exist in the country's right, but now, under the constitutional bias. The perspective, therefore, is twofold: to base, on the basis of fundamental rights, the full capacity of the disabled person; to recognize the consequent unconstitutionality of any rule that denies this capacity.

Keywords: New York Convention; Persons with Disabilities; Capacity; Fundamental Rights. 


\section{RESUMEN}

El texto tiene el propósito de describir el nivel en que se encuentra, en el derecho patrio, la protección de las personas con discapacidad. Para ello, se aborda la Convención de la ONU sobre el tema, su aprobación en Brasil como Enmienda Constitucional y la construcción de la legislación infraconstitucional correspondiente. Así, hay el intento de ofrecer fundamentos que permitan reconocer en la persona con discapacidad su absoluta capacidad, sin olvidar la merecida protección, por su diferencia, que sigue existiendo en el derecho patrio, pero, en adelante, bajo el sesgo constitucional. La perspectiva, por lo tanto, es de doble cara: de fundamentar, con base en los derechos fundamentales, la capacidad plena de la persona con discapacidad; de reconocer la consiguiente inconstitucionalidad de eventual norma que niegue esa capacidad.

Palabras clave: Convención de Nueva York; Personas con discapacidad; Capacidad; Derechos Fundamentales.

\section{SUMÁRIO}

INTRODUÇAO; 1 A PROTEÇÃO DAS PESSOAS COM DEFICIÊNCIA: A CONVENÇÃO DE NOVA IORQUE, A CONSTITUIÇÃO FEDERAL E O EPD; 1.1 O Direito ao Livre Desenvolvimento da Pessoa com Deficiência como Direito Fundamental; 20 ATUAL DEBATE SOBRE A CAPACIDADE CIVIL DA PESSOA COM DEFICIÊNCIA; 2.1 Um Novo Sistema de Incapacidades está em Construção; 30 PAPEL DO INTÉRPRETE NA CONCRETIZAÇÃO DA CONVENÇÃO DE NOVA IORQUE E DO EPD; CONCLUSÃO; REFERÊNCIAS.

\section{INTRODUÇÃO}

O patamar alcançado a partir do advento da Convenção da ONU sobre os Direitos das Pessoas com Deficiência, a chamada Convenção de Nova lorque, da qual o Brasil é parte, traz a expectativa da consolidação da igualdade, a partir do respeito às diferenças. A dita convenção teve sua promulgação interna a partir do Decreto Presidencial $n^{\circ}$ 6.949/09, após a aprovação, publicizada por meio do Decreto Legislativo $n^{\circ} 186 / 08$. Esta foi a primeira vez no ordenamento brasileiro em que o procedimento qualificado do $\S 3^{\circ}$, do Art. $5^{\circ}$ da Constituição Federal foi realizado, alçando a Convenção ao status de Emenda Constitucional.

A imposição do tratamento mais adequado às necessidades dos indivíduos atinge, posteriormente, sua estruturação de garantia a partir da edição da Lei $n^{\circ}$ 13.146/2015, o chamado Estatuto da Pessoa com Deficiência. A novel legislação trouxe a especificação e a pormenorização do que fora estabelecido pela Convenção, superando o contexto legislativo de tratamento discriminatório, conferido pelo Código Civil de $2002,{ }^{1}$ em seus artigos $3^{\circ}$ e $4^{\circ}$, que considerava as pessoas com deficiência incapazes de agirem por si próprias, tolhendo-lhes a autonomia.

\footnotetext{
1 BRASIL. Lei 10.406, de 10 de janeiro de 2002. Institui o Código Civil. Diário Oficial da União. Brasília: 10 jan. 2002. Disponível em: < https://www.planalto.gov.br/ccivil_03/LEIS/2002/L10406compilada.htm>. Acesso em: $01 \mathrm{dez} .2018$.
} 
Essa perspectiva teve origem no anterior regime, do Código Civil de $1916^{2}$, que, em seus artigos $5^{\circ}$ e $6^{\circ}$, que descrevia as pessoas com deficiência como "loucos de todo o gênero", de forma genérica e abstrata, em total descompasso com as realidades do mundo vivido.

A denominada teoria das incapacidades se explica na dual ideia de "capacidade de fato" e "capacidade de direito", nos termos do que dispôs o art. $1^{\circ}$ do Código Civil de 2002 e art. $2^{\circ}$ do Código de 1916 e, na perspectiva das pessoas com deficiência, conformava-lhes, repita-se, abstratamente, a condição de incapaz. Nesta perspectiva, as peculiaridades da pessoa eram desconsideradas e, por meio de processo de interdição, fixava-se a curatela geral, de forma que a representação ou assistência limitavam em absoluto o direito da pessoa de autodeterminação.

$O$ aludido estado de coisas recebe o giro copernicano com a entrada em vigor do Estatuto da Pessoa com Deficiência, que revoga expressamente a condição de incapaz da pessoa assim compreendida no texto legislado. Isso, no entanto, não foi uma vontade pura do legislador ordinário, mas uma obrigação decorrente do fato de a Constituição Federal de 1988 ter recepcionado como Emenda Constitucional a Convenção da ONU mencionada.

Essa perspectiva, no entanto, não é pacífica no que se refere à qualidade da proteção que a pessoa com deficiência recebe com a Convenção e com o EPD, especialmente pelo fato de que, ao deixar de ser incapaz, ela "perderia” as garantias que o Código Civil thes concede. Um exemplo inicial e pontual é o benefício de contra si não correr a prescrição. Por isso, no mesmo ano da publicação do Estatuto, teve início no Senado o PLS 757/2015 ${ }^{3}$ que, dentre outras propostas, pretende promover uma repristinação imprópria os arts. $3^{\circ}$ e $4^{\circ}$ do Código Civil de 2002.

A presente pesquisa tem por intuito apresentar algumas breves reflexões no sentido de contrariar essa reducionista compreensão, na tentativa de ofertar fundamentos que permitam reconhecer na pessoa com deficiência sua absoluta capacidade, sem olvidar da merecida proteção, por conta da sua diferença, que continua a existir no direito pátrio, mas, doravante, sob o viés constitucional, que permite um olhar hermenêutico-prospectivo sobre a legislação infraconstitucional.

O PLS 757/2015, como se verá, já nasce inconstitucional, por ofensa às garantias de autonomia e igualdade perante a lei de todas as pessoas, sobremodo aquelas com deficiência. A

\footnotetext{
2 BRASIL. Lei 3.071, de $1^{\circ}$ de janeiro de 1916. Código Civil dos Estados Unidos do Brasil. Diário Oficial da União. Rio de Janeiro: 5 jan. 1916. Disponível em: < https://www.planalto.gov.br/ccivil_03/Leis/L3071.htm>. Acesso em: 01 dez 2018.

3 Para conhecer o PLS 757/2015, acesse: http://www25.senado.leg.br/web/atividade/materias//materia/124251 Acesso em 10/08/2017.
} 
ISSN 1981-3694

(DOI): $10.5902 / 1981369432004$

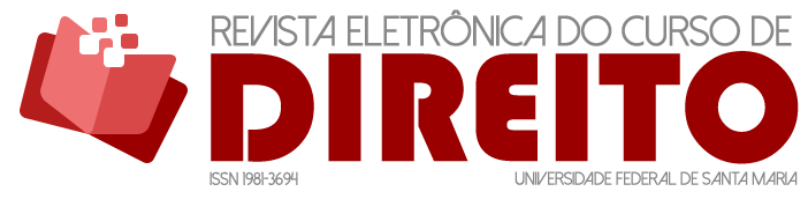

A INCONSTITUCIONALIDADE DA PROPOSTA DE RETORNO À INCAPACIDADE DA PESSOA COM DEFICIÊNCIA (PLS 757/2015) FRENTE À CONVENÇÃO DE NOVA IORQUE

interpretação, a integração e a aplicação do direito ao caso concreto, com hercúleo labor fulcrado nos direitos fundamentais e na sintonia teleológica, deve ser o norteador da construção de um modelo que fomente a consideração da pessoa a partir de suas potencialidades, desejo final da normatização internacional a que o Brasil aderiu.

A Convenção de Nova lorque - como também é denominada - foi recepcionada pelo direito brasileiro com a importante função de prestigiar a diversidade e conscientizar sobre a necessária proteção da autonomia e da igualdade das pessoas com deficiência, garantindo-lhes o livre desenvolvimento de suas personalidades, no contexto da dignidade, vez que direito fundamental. Mister compreender-se, portanto, o alcance do atual debate sobre a capacidade civil da pessoa com deficiência, como meio de trilhar de novos e mais humanos caminhos sobre o sistema (ou teoria) das (in)capacidades, para além da simples modificação legislativa.

Imperioso, nesse duto de ideias, que o poder público atue na proteção das pessoas com deficiência, nos moldes do que pretende a Convenção de Nova lorque e o EPD, inclusive e decisivamente por meio do Poder Judiciário, na concretização das promessas constitucionais de proteção dos direitos fundamentais.

\section{A PROTEÇÃO DAS PESSOAS COM DEFICIÊNCIA: A CONVENÇÃO DE NOVA IORQUE, A CONSTITUIÇÃO FEDERAL E O ESTATUTO DA PESSOA COM DEFICIÊNCIA}

O ser humano é complexo por natureza, e toda essa complexidade, a partir de conceitos nutridos na sociedade através dos séculos, por vezes resvalou no conceito de loucura, ou, ainda, em virtude de deformidades físicas, na ideia de monstruosidade. Todas as pessoas têm, em si, alguma "anormalidade", cabendo a cada qual proteger-se, no comportamento diário, das construções que os outros farão sobre sua personalidade e seu discernimento. 0 que se viu como “monstruosidade" na figura de Quasímodo no romance "O corcunda de Notre Dame”, de Victor Hugo, bem retrata o tom do tratamento em relação às pessoas tidas como "diferentes" ao longo dos tempos. Essas alegorias, contundentes, mas verdadeiras, não estão apenas no imaginário fictício, mas permeiam as vidas das pessoas que convivem com algum traço físico ou psíquico diverso do "socialmente perfeito".

Com vistas a uma tentativa de pôr fim a esses (pré-)conceitos livremente formados, a Convenção de Nova lorque conceitua a pessoa com deficiência como aquela que, por questões de 
ISSN 1981-3694

(DOI): $10.5902 / 1981369432004$

“impedimentos de longo prazo de natureza física, mental, intelectual ou sensorial, os quais, em interação com diversas barreiras, podem obstruir sua participação plena e efetiva na sociedade em igualdades de condições com as demais pessoas”. Como já se viu- a mencionada Convenção trouxe à luz tratamento jurídico uniforme para as pessoas com deficiência, na intenção de garantir-lhes seus direitos fundamentais. O documento foi extraído de encontro promovido pela ONU, em Nova lorque, no ano de 2007.

Esse conjunto normativo teve seu protocolo facultativo subscrito pelo Brasil, com ratificação pelo Congresso Nacional em Decreto Legislativo $\mathrm{n}^{\circ} 186$, de 9 de julho de 2008, em conformidade com o procedimento previsto no $\S 3^{\circ}$ do art. $5^{\circ}$ da Constituição Federal. Encontrase em vigor para o Brasil, no plano jurídico externo, desde 31 de agosto de 2008, e promulgados pelo Decreto no 6.949 , de 25 de agosto de 2009, data de início de sua vigência no plano interno. ${ }^{4}$

Considerando-se o teor do $\S 3^{\circ}$ do $5^{\circ}$, da Constituição - inserido pela Emenda Constitucional $n^{\circ} 45$, da Reforma do Judiciário - os tratados internacionais de direitos humanos, cumprido o procedimento ali determinado, ingressam no ordenamento jurídico interno como emendas constitucionais, o que torna a Convenção parte da Constituição.

Com a realização do procedimento previsto pela aludida Emenda Constitucional, portanto, não há mais incapacidade para pessoas com deficiência no Brasil, especialmente por conta de seu art. 12, que estabelece que as pessoas com deficiência "gozam de capacidade legal em igualdade de condições com as demais pessoas em todos os aspectos da vida". A Convenção determina, nas obrigações gerais para os Estados Parte, no item 1.a., que cada qual deva: “[...] adotar todas as medidas legislativas, administrativas e de qualquer outra natureza, necessárias para a realização dos direitos reconhecidos na presente Convenção".

Por conta disso é que nasce a Lei Brasileira de Inclusão - Lei n 13.146 de 06 de julho de 2015 - que, em seu art. $1^{\circ}$, se auto denomina como "Estatuto da Pessoa com Deficiência", destinado "a assegurar e a promover, em condições de igualdade, o exercício dos direitos e das liberdades fundamentais por pessoa com deficiência, visando à sua inclusão social e cidadania." Ela é composta de uma parte geral, que determina a igualdade e não discriminação, a qual trata dos direitos fundamentais, da acessibilidade, e norteia campos como o da ciência e da tecnologia, na intenção de promover o desenvolvimento da pessoa; e de uma parte especial, que determina regramento sobre o acesso à justiça, fixa sanções de índole criminal para quem

${ }^{4}$ Vide art. $1^{\circ}$, parágrafo-único, do Lei 13.146/15. 
desrespeitar os comandos da lei e fixa disposições gerais e transitórias, para o poder público e para a sociedade.

0 presente texto, nesse duto de ideias, elege como premissa metodológica recortar essa gama de informações em duas: (a) a capacidade plena da pessoa com deficiência e (b) a consequente inconstitucionalidade de eventual norma que negue essa capacidade. Tudo, com norte nos direitos fundamentais. Faz-se necessário, portanto, edificar-se fundamento para a interpretação do conjunto normativo em benefício das pessoas com deficiência, sem que seja necessário catalogá-las como incapazes.

\subsection{O Direito ao Livre Desenvolvimento da Pessoa com Deficiência como Direito}

\section{Fundamental}

A pessoa com deficiência tem constitucionalmente assegurado o direito de livremente determinar-se e desenvolver todos os atributos de sua personalidade, eis que preserva e reforça sua dignidade. A capacidade liberta e permite que a pessoa possa agir em todos os atos da vida civil que consiga, com apoio - por tomada de decisão apoiada ou curatela - quando for necessário, sempre merecendo ressaltar que a curatela não é mais total, mas densificada e fixada pelo juiz para atos específicos a que a pessoa necessitar.

Como bem frisado por Luiz Alberto David Araujo e Carlos Eduardo Pianovski Ruzyk:

Inegável que a regra do "tudo ou nada" foi proibida pela Convenção. Na prática, era comum decretar-se a interdição para todos os atos da vida civil. E, com isso, havia uma restrição completa ao exercício da cidadania da pessoa, mesmo que ela pudesse praticar determinados atos. Mesmo que a pessoa fosse qualificada como relativamente incapaz, a restrição não se vinculava às potencialidades da pessoa, mas, simplesmente, em um status definido abstratamente pela norma do artigo $4^{\circ}$ do Código Civil. Vejamos um exemplo bem singelo. Uma pessoa com limitações intelectuais pode, perfeitamente, ir à padaria, comprar pão, leite, fazer pequenas transações, sem qualquer necessidade de atuação de seu curador. Esse gesto, que pode parecer simples para muitos, pode representar um grande momento na vida dessa pessoa, entregando-lhe a responsabilidade desse ato, que colaborará para a sua inclusão social, dentro dos limites de sua capacidade e de sua segurança. ${ }^{5}$

\footnotetext{
${ }^{5}$ ARAÚJO, Luiz Alberto David; Ruzyk, Carlos Eduardo Pianovski. A perícia multidisciplinar no processo de curatela e o aparente conflito entre o estatuto da pessoa com deficiência e o código de processo civil: reflexões metodológicas à luz da teoria geral do direito. R. Dir. Gar. Fund., Vitória, v. 18, n. 1, p. 227 256, jan./abr. 2017. p. 232.
} 
De fato, a curatela é medida a ser analisada caso a caso, com vistas a alcançar a exata necessidade da pessoa a ser apoiada e auxiliada nos exatos procedimentos da vida em que the seja necessário. Não existe mais, e parece de todos sabido, a curatela absoluta e para todos os atos, conforme determina o art. 84, $\S 3^{\circ}$, do Estatuto da Pessoa com Deficiência. Para que se efetivem restrições à autonomia da pessoa, mister que se apure, como afirmam Ana Luiza Maia Nevares e Anderson Schreiber, "o discernimento e interesse subjacente à situação subjetiva em concreto". ${ }^{6}$

A regra anterior de incapacidade legal prevista nos arts. $3^{\circ}$ e $4^{\circ}$ do Código Civil discriminava mais do que protegia, pelo fato de que era regra abstrata e geral, rotulando a todas as pessoas que pudessem ter algum grau ou espécie de deficiência, que invariavelmente alcançava o agressivo resultado de um processo de interdição, no qual se thes restringiam todas as atitudes, quer de intimidade, quer de patrimônio.

Aponte-se, como exemplo, caso real de jovem com Síndrome de Down, mas que tem a total consciência de tudo ao seu redor e consegue livremente desenvolver sua vida, estudando, trabalhando, namorando e vivendo em plena integração social. Não obstante a tudo isso, sua mãe teme por algumas atitudes, vez que em situações muito específicas, quando em contato com excessivo barulho, o jovem por ter surtos. Seria gravemente ofensiva a atribuição, ao jovem rapaz, da condição de incapaz. Da mesma forma, sofreria sobremaneira, em participar de processo de interdição. A tomada de decisão apoiada é o meio mais adequado, menos ofensivo e mais eficaz.

Em outras palavras, a realidade da vida e a praxis, demonstram, também, que a Convenção de Nova lorque, ao estipular no art. 12.2 que "os Estados reconhecerão que as pessoas com deficiência gozam de capacidade legal em igualdade de condições com as demais pessoas em todos os aspectos da vida”, acertou, vez que, no exemplo, mencionado não há qualquer diferença entre o jovem com Síndrome de Down e qualquer outro jovem, em qualquer condição.

É evidente que jovem com Síndrome de Down demanda cuidados e, em alguns momentos, deve ser considerado em suas peculiaridades, afinal é pessoa com deficiência. Não há, entretanto, qualquer razoabilidade em considerá-lo incapaz para todos os atos. Basta que se

\footnotetext{
6 NEVARES, Ana Luiza Maia Nevares; SCHREIBER, Anderson. Do sujeito à pessoa: uma análise da incapacidade civil. In: TEPEDINO, Gustavo; TEIXEIRA, Ana Carolina Brochado; ALMEIDA, Vitor. [coords]. 0 direito civil ente o sujeito e a pessoa: estudos em homenagem ao professor Stefano Rodotà. Belo Horizonte: Editora Fórum, 2016. p. 55.
} 
faça como determina o art. 12.3, ou seja, “os Estados Partes tomarão medidas apropriadas para promover o acesso das pessoas com deficiência ao apoio que necessitarem no exercício de sua capacidade legal."

A Convenção, cuja natureza jurídica é de norma constitucional, como já foi adrede mencionado, especifica textualmente que a pessoa com deficiência é capaz, no sentido de ter capacidade legal, e que esta capacidade não é, nem de longe, somente a capacidade de direito. Trata-se de capacidade de fato, de exercício, pois se assim não fosse não estaria explicitado "em igualdade de condições com as demais pessoas em todos os aspectos da vida" (art. 12.2, parte final). A capacidade liberta e densifica o princípio da dignidade humana, na exata dimensão acima, ou seja, a pessoa com deficiência se sente inserida na vida e na igualdade que deve existir entre ela e todas as demais pessoas.

A Constituição Federal de $1988,{ }^{7}$ ainda, protege expressamente a pessoa com deficiência em diversos momentos, especificamente nos arts. $7^{\circ}$, XXXI; art. 23, II; 24, XIV; art. 37, VIII; art. 203, IV, V; art. 208, III, IV; art. 227, §1, II, §2; art. 244.

Rubens Limongi França, ${ }^{8}$ saudoso jurista, entendia que os direitos da personalidade podiam ser classificados e explicados a partir da perspectiva de integridade. A Convenção de Nova lorque também caminhou nesse sentido ao determinar no art. 17 que "toda pessoa com deficiência tem o direito a que sua integridade física e mental seja respeitada, em igualdade de condições com as demais pessoas" e essa integridade tem a ver com a liberdade de autodeterminação. A Constituição, como visto, determina que o Estado não somente não impeça, como fomente a construção da capacidade da pessoa com deficiência em condição igual com as demais pessoas. Isso serve, também, como elemento de densificação do princípio da igualdade, que é direito fundamental.

A pessoa não se desenvolve livremente se for incapaz, por não poder autodeterminar-se e agir em condição de igualdade com os demais. A Convenção repete algumas dezenas de vezes a oração “em condições de igualdade com as demais pessoas” e não é sem razão. Não é a designação e o rótulo de incapaz que vão proteger a pessoa com deficiência.

No sentido da Convenção, e para complementar seu aspecto normativo, o art. $6^{\circ}$ do EPD garante a capacidade das pessoas com deficiência, ${ }^{9}$ especificando cuidadosamente diversos

\footnotetext{
7 BRASIL. Constituição Federal. Diário Oficial da União. Brasília: 5 out. 1988. Senado Federal, 1988. Disponível em: <http://www.planalto.gov.br/ccivil_03/Constituicao/Constituiçao.htm>. Acesso em: 01 dez. 2018.

${ }^{8}$ FRANÇA, Rubens Limongi. Instituições de Direito Civil. São Paulo: Saraiva, 1988, v. 1. p. 43

${ }^{9}$ Art. 60 A deficiência não afeta a plena capacidade civil da pessoa, inclusive para:
} 
aspectos da vida em sociedade, cuja dúvida poderia surgir ao intérprete. 0 art. 84, mantendo a mesma sintonia, esclarece que a pessoa com deficiência tem assegurado o direito ao exercício de sua capacidade legal em igualdade de condições com as demais pessoas. Como já se vinha expondo neste texto, quando houver necessidade a pessoa será submetida a curatela ou tomada de decisão apoiada, mas, sempre, como determina $0 \$ 3^{\circ}$ do dito artigo, proporcional às necessidades e às circunstâncias de cada caso, sendo que esta intervenção subsistirá pelo menor tempo possível.

Em outras palavras, é direito fundamental da pessoa com deficiência ser considerada e reconhecida, jurídica e socialmente, como capaz. Essa fundamentalidade está densificada nas aplicações do princípio da igualdade até agora reiteradas, que convergem em igual preenchimento dos elementos necessários para bem construir a dignidade da pessoa humana neste contexto.

De tudo isso, poder-se-ia indagar qual o modo de se proteger a pessoa com deficiência se apenas os incapazes têm "prerrogativas" na lei (exemplo reiterado da não ocorrência da prescrição para os absolutamente incapazes). A resposta somente pode ser construída após alguma análise acerca do estado da arte do tema, em termos doutrinários. 0 que se fará em seguida, ainda que de forma breve.

\section{A DOUTRINA E O DEBATE SOBRE A CAPACIDADE CIVIL DA PESSOA COM DEFICIÊNCIA}

A clássica lição de Clóvis Beviláqua, ${ }^{10}$ ao tratar do art. $2^{\circ}$ do Código Civil de $1916,{ }^{11}$ de que a capacidade de direito todos tem - sinônimo de personalidade jurídica da pessoa natural -,

I - casar-se e constituir união estável;

II - exercer direitos sexuais e reprodutivos;

III - exercer o direito de decidir sobre o número de filhos e de ter acesso a informações adequadas sobre reprodução e planejamento familiar;

IV - conservar sua fertilidade, sendo vedada a esterilização compulsória;

$V$ - exercer o direito à família e à convivência familiar e comunitária; e

$\mathrm{VI}$ - exercer o direito à guarda, à tutela, à curatela e à adoção, como adotante ou adotando, em igualdade de oportunidades com as demais pessoas.

10 BEVILÁQUA, Clovis. Codigo civil dos Estados Unidos do Brasil. São Paulo/Belo Horizonte: Livraria Francisco Alves, 1921. v. 1. p. 165.

11 "Capacidade é e extensão dada aos poderes de acção, contidos na personalidade. Neste artigo, não se trata de capacidade de facto, que é o limite da personalidade. Aqui o Codigo define, antes, a personalidade, que equivale á capacidade de direito. Affirma que todo homem é pessôa, no sentido jurídico da expressão." (sic) 
mas a capacidade de fato - também chamada de exercício - exige a complementação do agir pelo atuar de um representante (incapacidade absoluta) ou de um assistente (incapacidade relativa), sobrevive até os dias atuais.Esse estado de coisas, no que se refere às pessoas com deficiência, vigorou até a chegada, entre nós, da Convenção de Nova lorque e do Estatuto da Pessoa com Deficiência, como já bem visto.

A referida lei cria uma nova teoria das incapacidades dentro do direito civil brasileiro, reduzindo hipótese de incapacidade por questão de "saúde" tão somente àqueles que, por causa transitória ou permanente, não puderem exprimir sua vontade (atual art. 4, III, do Código Civil). Não obstante, ainda está em construção no Brasil a consciência da força normativa da Constituição, ou seja, lamentavelmente grande parte dos juristas insistem em privilegiar a lei ordinária à Constituição, em absoluto demérito à hierarquia das normas.

Por este motivo, é voz corrente que foi o Estatuto a efetivar a alteração do ordenamento jurídico brasileiro, e não a Convenção que, infelizmente, muitos sequer conhecem. Nesse caminho tortuoso, acaba-se por fomentar razoável confusão na compreensão do novo sistema, em detrimento do Direito e das realidades das pessoas.

José Fernando Simão ${ }^{12}$ entende que o EPD, no tema da capacidade, é mais prejudicial do que vantajoso para a pessoa com deficiência, tendo sido inclusive seus ensinamentos utilizados como fundamento do PLS 757/2015 que ora se questiona. Para ele, somente os incapazes podem fazer uso das prerrogativas legais, como por exemplo, a do art. 198, III, do Código Civil. Por este motivo, estariam as pessoas com deficiência alijadas, na medida em que são capazes pelo novo modelo normativo. ${ }^{13}$

\footnotetext{
12 SIMÃO, José Fernando. Estatuto da Pessoa com Deficiência causa perplexidade (Parte I). CONJUR, 06 de agosto de 2015. Disponível em: <http://www.conjur.com.br/2015-ago-06/jose-simao-estatuto-pessoadeficiencia-causa-perplexidade>. Acesso em: 05 dez. 2018.

13 "Sendo o deficiente, o enfermo ou excepcional pessoa plenamente capaz, não poderá ser representado nem assistido, ou seja, deverá praticar pessoalmente os atos da vida civil. Mas há um problema prático: apesar de o Estatuto ter considerado tal pessoa capaz, na vida cotidiana tal pessoa não consegue exprimir sua vontade. Há pessoas que por fatores físicos são incapazes de manifestar sua vontade, mas passam a ser capazes por força da nova lei. Assim indago: qual o efeito prático da mudança proposta pelo Estatuto? Esse descompasso entre a realidade e a lei será catastrófico. Com a vigência do Estatuto, tais pessoas ficam abandonadas à própria sorte, pois não podem exprimir sua vontade e não poderão ser representadas, pois são capazes por ficção legal. Como praticarão os atos da vida civil se não conseguem fazê-lo pessoalmente? A situação imposta pelo Estatuto às pessoas que necessitam de proteção é dramática. Trouxe, nesse aspecto, o Estatuto alguma vantagem aos deficientes? A mim, parece que nenhuma." In: SIMÃO, José Fernando. Estatuto da Pessoa com Deficiência causa perplexidade (Parte I). CONJUR, 06 de agosto de 2015. Disponível em: <http://www.conjur.com.br/2015-ago-06/jose-simaoestatuto-pessoa-deficiencia-causa-perplexidade>. Acesso em: 25 jul. 2016.
} 
ISSN 1981-3694

(DOI): $10.5902 / 1981369432004$

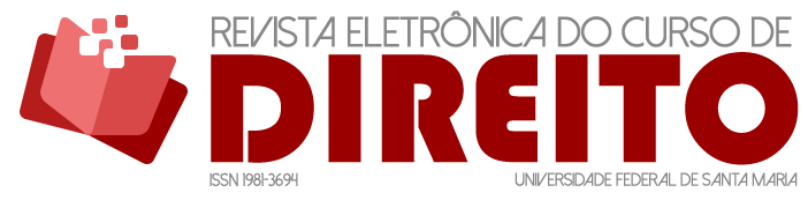

A INCONSTITUCIONALIDADE DA PROPOSTA DE RETORNO À INCAPACIDADE DA PESSOA COM DEFICIÊNCIA (PLS 757/2015) FRENTE À CONVENÇÃO DE NOVA IORQUE

Já defendemos em outras oportunidades, ${ }^{14}$ na linha de Paulo Lôbo ${ }^{15}$ e Joyceane Bezerra de Menezes que a Convenção de Nova lorque permite a proteção das pessoas com deficiência em sintonia com as premissas da curatela e da tomada de decisão apoiada, possibilitando de acordo com o caso concreto a mesma proteção concedida aos incapazes.

Este texto caminha no sentido destas últimas ideias, ou seja, crê-se na efetiva intenção de modificar o sistema clássico de incapacidades, retirando qualquer pessoa que tenha deficiência de seu alcance, mas permitindo-se interpretação normativa que favoreça a extensão de direitos. Acredita-se, portanto, que foi essa a intenção da Convenção a que o Brasil aderiu, e por conta do que se obrigou a implementar a legislação e a instrumentalizar os direitos garantidos na norma internacional.

Cabe ao Direito se amoldar às contemporâneas realidades dessas pessoas que carecem de proteção, respeito, igualdade e afirmação na sociedade, e não estas se manterem adequando forçadamente aos antigos postulados jurídicos da incapacidade, tão somente por conta da cultura jurídica e da tradição histórica de um formato normativo. Nesse contexto, faz-se imediato que se abram mentes e corações para uma nova realidade: a da plena capacidade das pessoas com deficiência, através da pavimentação de uma vereda que seja construída com mais humanidade, edificando-se um sistema de capacidades, superando-se o anterior, de incapacidades.

\subsection{Um Novo Sistema de Incapacidades está em Construção}

O novo sempre causa perplexidade e suas consequências costumam gerar sentimento de insegurança e temor. Não poderia ser diferente quando se fala em tema tão relevante quanto o do trato das situações que envolvem a capacidade civil. A técnica das incapacidades, por se tratar de preceito clássico que remonta à origem do direito brasileiro desde as ordenações, reside no imaginário dos partícipes do fenômeno jurídico e dificilmente será dele retirado.

O conhecimento mediante repetição é tradicional e quaisquer propostas de novas ideias terão, em geral, acentuada dificuldade de se firmar nos cenários da índole jurídica. Não se nega

\footnotetext{
${ }^{14}$ SILVA, Alexandre Barbosa da. O Estatuto da Pessoa com Deficiência e o Regime das Incapacidades: Breve Ensaio sobre Algumas Possibilidades. In: EHRARDT JUNIOR, Marcos [coord]. Impactos do novo CPC e do EPD no direito civil brasileiro. Belo Horizonte: Editora Fórum, 2016. P. 241-256

15 LÔBO, Paulo. Com avanços legais, pessoas com deficiência mental não são mais incapazes. CONJUR, 16 de agosto de 2015. Disponível em: <http://www.conjur.com.br/2015-ago-16/processo-familiaravancos-pessoas-deficiencia-mental-nao-sao-incapazes>. Acesso em: 25 jul. 2016.
} 
a existência de equívocos no Estatuto da Pessoa com Deficiência, mas os ajustes necessários estão muito para aquém da necessidade de se modificar a perspectiva de capacidade.

Exemplo de tema que merece revisão é a inserção de pessoa que por causa transitória ou permanente não possa expressar sua vontade como relativamente incapaz (art. 4, III, do CC), como é o caso das pessoas em coma hospitalar. Em verdade, esta pessoa não se coloca coerentemente como relativamente incapaz, até porque sua condição não é de possibilidade parcial de agir, como é típico das causas de incapacidade relativa descritas no art. $4^{\circ}$, mas de absoluta necessidade de representação, para a qual nao basta mera assistência.

Mas, a partir disso, pretender "repristinar" a totalidade do art. $3^{\circ}$, confundindo situações que envolvam falta de discernimento ou de possibilidade de expressá-lo, com as condições peculiares das pessoas com deficiência, não soa compatível com a Convenção de Nova lorque. Veja-se a pretensão do PLS 757/2015:

Já no seu art. $2^{\circ}$, revoga os incisos II, IV, VI e VII do art. 123 do Estatuto da Pessoa com Deficiência, os quais por sua vez revogaram incisos do Código Civil. Assim, a proposição em análise intenciona tornar sem efeito a revogação, pelo mencionado Estatuto, dos seguintes dispositivos do Código Civil:

i) Os incisos I, II e III do art. $3^{\circ}$, os quais definem os absolutamente incapazes de exercer pessoalmente os atos da vida civil. ${ }^{16}$

Veja-se, inclusive, que existe em trâmite Substitutivo do PLS 757/2015, no qual passa desapercebido do legislador que o art. 114 do Estatuto especificou a revogação dos incisos I, II e III do art. $3^{\circ}$, e modificou o art. $4^{\circ}$ e seus incisos, o que torna insuficiente a revogação dos incisos do art. 123 descrito. Não obstante, mais consentâneo com a nova ordem internacional estatuída com a Convenção de Nova lorque, reconhecida - repita-se, como Emenda Constitucional no direito interno - será modificar os arts. $3^{\circ}$ e $4^{\circ}$, tão somente inserindo no art. $3^{\circ}$ as pessoas que não consigam expressar sua vontade, por coma ou outra situação semelhante, bem como modificando o art. $4^{\circ}$ para excluir esta situação.

Veja-se que a pessoa em situação de coma, ou análogo, não se encaixa na condição daquela com deficiência. Alguém que tenha deficiência, em qual grau for, ainda que com dificuldade de se expressar, merece a consideração da Convenção e do Estatuto e deve ser

16 BRASIL. Senado Federal. Projeto de Lei do Senado 757/2015. Altera a Lei $n^{\circ} 10.406$, de 10 de janeiro de 2002 (Código Civil), a Lei n 13.146, de 6 de julho de 2015 (Estatuto da Pessoa com Deficiência), e a Lei $\mathrm{n}^{\circ}$ 13.105, de 16 de março de 2015 (Código de Processo Civil), para dispor sobre a igualdade civil e o apoio às pessoas sem pleno discernimento ou que não puderem exprimir sua vontade, os limites da curatela, os efeitos e o procedimento da tomada de decisão apoiada. Disponível em: < https://www25.senado.leg.br/web/atividade/materias/-/materia/124251 >. Acesso em: 07 dez. 2018. 
ISSN 1981-3694

(DOI): $10.5902 / 1981369432004$

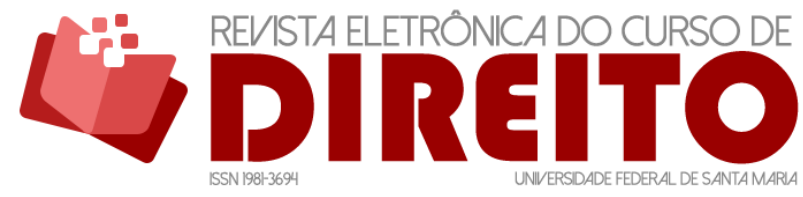

A INCONSTITUCIONALIDADE DA PROPOSTA DE RETORNO À INCAPACIDADE DA PESSOA COM DEFICIÊNCIA (PLS 757/2015) FRENTE À CONVENÇÃO DE NOVA IORQUE

legalmente capaz. E ainda que o PLS 757/2015 queira regrar de forma exauriente o prestígio à pessoa com deficiência, como diz pretender, não será pelo retrocesso da fixação da pessoa como incapaz que conseguirá.

Imaginando-se, no entanto, que o absoluto apego à letra da lei se mantenha, ${ }^{17}$ e o legislador queira formular alguma alteração legislativa, não será da forma como está acontecendo que se terá êxito em cumprir as promessas da Convenção e da Constituição.

$\mathrm{Na}$ hipótese de se desejar alterar a lei, que seja por outros dispositivos que não os artigos $3^{\circ}$ e $4^{\circ}$, tornando-se à incapacidade, mas, sim, alterações pontuais em diversos conteúdos do Código Civil, do Estatuto da Pessoa com Deficiência e do Código de Processo Civil, que possibilitem a exata e indiscutível proteção da pessoa, permitindo-se à pessoa com deficiência a mesma proteção concedida às pessoas incapazes.

Para facilitar a compreensão da proposta, cita-se o art. 198 do Código Civil, que determina não correr a prescrição contra os incapazes de que fala o art. $3^{\circ}$. Fácil inserir, na letra da lei, tão somente o seguinte: “Art. 198. Também não corre a prescrição: I - contra os incapazes de que trata o art. $3^{\circ}$ e contra as pessoas com deficiência”. Essa pequena alteração poderia, de maneira simples e sem ferimento da Convenção e do Estatuto, solucionar a problemática que gera o temor dos juristas e que fundamenta o PLS 757/2015. Apenas não é plausível retroceder na garantia de igualdade das pessoas com deficiência em relação às demais, como bem determina o art. 12 da Convenção sobre Direitos da Pessoa com Deficiência multimencionada.

Não se trata apenas de mera pretensão hipócrita de manter uma forma de tratamento, em prejuízo de outros direitos. Poder-se-ia afirmar que se trata tão somente de atribuir uma capacidade “de papel” à pessoa com deficiência, ao passo que, na verdade, estará prejudicada pela realidade de ver subtraídos direitos outrora consolidados pela lei civil. Ora, se a preocupação é com a letra da lei - o que se justifica diante da prática civil lamentavelmente legalista que reina no país, por operadores do direito em geral - que se promovam alterações pontuais no Código Civil fazendo-se com que os benefícios outorgados aos incapazes também se reflitam na realidade das pessoas com deficiência. Criticável é voltar no tempo, erroneamente, para, sob o pretexto de proteção, retornar pessoas que necessitam de acesso à igualdade e à autonomia para a condição de incapazes.

17 Em situação oposta à que será objeto de sugestão adiante, ou seja, técnicas hermenêuticas para construir decisão favorável à pessoa com deficiência. 
Ademais, o Estatuto determina, em seu art. $8^{\circ}$, a prioridade de tratamento da pessoa com deficiência, assemelhando-se, em alguma medida, ao que se dispensa a crianças e adolescentes (art. $227 \mathrm{CF}, 4^{\circ} \mathrm{ECA}$ ). Ainda que se conheça a crítica de Lenio Streck à criação exagerada de princípios jurídicos no Brasil $^{18}$ certamente a doutrina tende a construir que as pessoas com deficiência se vejam assistidas por um verdadeiro "princípio de prioridade”, que deve servir de base, um verdadeiro padrão interpretativo da extensão de direitos e garantias constitucionais. Princípio ou não, o padrão de prioridade de tratamento à pessoa com deficiência justifica a aplicação extensiva dos direitos que são deferidos aos incapazes, sem que precisem de tal estigmatização.

Por outro lado, o art. $6^{\circ}$ da Lei de Inclusão esclarece que a deficiência não afeta a plena capacidade civil da pessoa. Na mesma dicção, o art. 84, que assegura o direito ao exercício da capacidade legal. Não há margem para dúvidas sobre a mudança do sistema de incapacidades. 0 PLS n 757/2015 e seu Substitutivo não contemplam modificação deste novo modelo legal.

Há quem afirme que a capacidade legal descrita no art. 84 é a capacidade de direito, que todos têm. Não parece razoável, entretanto, uma vez que, se todos têm a capacidade de direito, não haveria motivos para reiterá-la aqui. Ademais, a ideia é firmar-se a modificação da esfera de direitos, para a igualdade, a não discriminação e a autonomia.

Modificar outros artigos específicos - como o art. 123 - de nada adiantará para fragilizar a convicção de que a pessoa com deficiência é plenamente capaz. Isso, por conta da perspectiva da lei, que sintoniza com a Convenção de Nova lorque, recepcionada pelo direito interno em nível constitucional. Claro, portanto, que o Estatuto não é o principal criador da capacidade da pessoa com deficiência, mas, sim, a Emenda Constitucional veiculada pelo Convenção e seu Protocolo Facultativo. A boa coerência e compreensão normativa não devem permitir que se altere a base do novo sistema, com a retomada da incapacidade absoluta da pessoa com

\footnotetext{
18 Vide: STRECK, Lênio Luiz. Verdade e consenso: constituição, hermenêutica e teorias discursivas. 4. ed. São Paulo: Saraiva, 2011. p. 517 e seguintes. Para uma mais rápida análise da crítica do autor, veja o resumo do pensamento: "De certo modo, impressiona-me o fato de que parcela dos juristas que dá razão à juíza não questiona o fato de a colegialidade ser um princípio. Parece normal que se diga "principio da colegialidade"... Ora, parece-me que este o cerne "dogmático" do problema. De fato, temos de revisar o nosso conceito acerca do que seja um princípio. É a confiança do juiz da causa, a rotatividade, afetividade, conectividade...0 que mais vão inventar? Por que (e para quê) fazer leis, se os juristas podem construir/inventar "princípios" no atacado? E os próprios juristas não se dão conta disso. Um princípio não é um valor. Valor é coisa contingente. Princípio não é o canal para a moralização do direito. E nem para a desmoralização, se me entendem a ironia. Princípio é norma. E não algo à disposição do intérprete." STRECK, Lênio Luiz. O fator stoic mujic, a juíza Kenarik e o papel dos advogados, hoje! CONJUR, 11 de fevereiro de 2016. Disponível em: <http://www.conjur.com.br/2016-fev-11/senso-incomum-fator-stoicmujic-juiza-kenarik-papel-advogados-hoje>. Acesso em 26 jul. 16.
} 
deficiência, sob pena de ser, de imediato, fulminada pela inconstitucionalidade, por afronta à Convenção Internacional.

Por outra via, o PLS 757/2015 pode - se devidamente readequado - promover coerência na formatação do novo sistema ao inserir, como visto, as pessoas em situações como a da quem se encontre em estado de coma, no rol dos absolutamente incapazes, ao invés de relativamente incapazes. É possível, ainda, a correção de rumo no que pertine à dicotomia entre o Código Civil e o Código de Processo Civil acerca da Decretação de Curatela e a Interdição. Paulo Lôbo acertadamente frisa que o Estatuto da Pessoa com Deficiência objetivou excluir a ação de interdição do sistema jurídico brasileiro. Assim analisa, porque esta sempre teve por finalidade vedar o exercício, pela pessoa com deficiência mental ou intelectual, de todos os atos da vida civil, impondo-se a mediação de seu curador. ${ }^{19}$

O Parecer de Flávio Tartuce ao PLS 757/2015 e ao Substitutivo protocolado é exatamente nesse sentido, como o que se concorda enfaticamente. ${ }^{20}$ Não há mais espaço no sistema para a interdição. 0 motivo não é, reitere-se, mero jogo de palavras, e sim a carga discriminatória que o conteúdo da medida traz histórica e juridicamente. Isso porque a ideia sobre interdição sempre foi a de excluir a pessoa com deficiência da tomada de decisões. 0 próprio vocábulo expressa proibição, vedação, veto, o que é incompatível com a natureza da nova consideração atinente a essas pessoas.

Para além da antiga ideia de substituição da vontade da pessoa com deficiência, o que se deseja, agora, é a colaboração, o apoio. O suprimento da vontade somente acontecerá em hipóteses específicas em que a pessoa não conseguir expressar adequadamente sua intenção, com a atuação do curador ou do apoiador. A curatela atual, portanto, como evolução da interdição, deve ser para uma atuação de apoio, de auxilio, que permita à pessoa com deficiência desenvolver coerentemente as esferas de sua personalidade na vida cotidiana. Da mesma maneira nos casos mais simples de deficiência, em que será possível a nomeação de apoiador, na Tomada de Decisão Apoiada.

Note-se que sob a sistemática anterior das incapacidades, os negócios aconteciam normalmente, com seus normais prejuízos decorrentes das manifestações de vontade de pessoas com deficiência não interditadas. Os arts. $3^{\circ}$ e $4^{\circ}$ não guardavam aplicação direta e objetiva, eis

\footnotetext{
19 Lôbo, Paulo. Com avanços legais, pessoas com deficiência mental não são mais incapazes. CONJUR, 16 de agosto de 2015. Disponível em: <http://www.conjur.com.br/2015-ago-16/processo-familiaravancos-pessoas-deficiencia-mental-nao-sao-incapazes>. Acesso em 25 jul. 2016.

${ }^{20}$ Para se analisar o parecer de Flávio Tartuce, basta acessar o link já indicado do PLS 757/2015.
} 
ISSN 1981-3694

(DOI): $10.5902 / 1981369432004$

que dependiam da ação de interdição para que se considerassem incapazes os que padecessem de alguma espécie de peculiar condição.

Nessa perspectiva, atualmente, se negócios forem realizados por pessoa com deficiência que tenham sido enganadas ou que porventura prejudiquem terceiros, a medida, na prática, será a mesma: a ação de anulação. Não mais por incapacidade de uma ou ambas as partes, mas por conta de sua condição de pessoa com deficiência, em situações de não participação de apoiadores ou curadores. Será necessária a consideração da nulidade, absoluta ou relativa, pelas condicionantes do próprio negócio realizado com quem não tenha conduções de bem expressar sua vontade.

A diferença é que se terá de levar em conta aspectos objetivos, ligados à concretude dos casos, para além de mera interdição previa. Isso, todavia, já acontecia. Se ficar constatado que a pessoa com deficiência sofreu - ou gerou - prejuízo, pela própria natureza do direito negocial e contratual contemporâneos, o negócio poderá ser desfeito, com a demonstração da quebra da boa-fé, da alteridade e/ou da solidariedade.

Esses elementos que denotam a nova contratualidade, resultam da superação do individualismo da modernidade e da consciência de que ninguém vive sozinho, devendo haver colaboração recíproca nas relações interpessoais que se projetam no trânsito jurídico, nas titularidades e no projeto parental. Em outras palavras, é o pensar no outro, é superar a crise ética do individualismo - ainda crescente - por meio do qual cada pessoa deseja seus próprios êxitos ainda que à custa do prejuízo - patrimonial ou não patrimonial - alheio.

Paulo Lôbo, nesse sentido, afirma que:

A solidariedade, como categoria ética e moral que se projetou para o mundo jurídico, significa um vínculo de sentimento racionalmente guiado, limitado e autodeterminado que impõe a cada pessoa deveres de cooperação, assistência, amparo, ajuda e cuidado em relação às outras. ${ }^{21}$

Acreditar que a incapacidade protegerá a pessoa com deficiência é por demais superficial e incompleto. A proteção deve partir de uma perspectiva conjuntural, a partir da interpretação dos novos paradigmas trazidos pela Convenção de Nova lorque e pelo Estatuto da Pessoa com Deficiência, tais como a prioridade de tratamento e proteção, bem descritos em diversos momentos de ambas as normas.

${ }^{21}$ LÔBO, Paulo. Direito civil: parte geral. São Paulo: Saraiva, 2009. p. 81. 
As demandas sociais complexas não se enquadram mais no antigo e simplificado juízo silogístico. Os novos acontecimentos, especialmente no direito civil, estão para além da letra da lei e não se permitem meramente "encaixar-se" no texto positivado. Negar-se a alguém um bem da vida pelo simples fato de que "não é capaz", pelo único motivo de não atender a um enquadramento codificado incapacitante, sem que the seja possível a demonstração de suas razões, é fazer das promessas constitucionais algo meramente figurado, na medida em que se descumpre um dos mais importantes objetivos da República, que é o de construir uma sociedade justa e solidária.

Luiz Edson Fachin auxilia na reflexão quando orienta que:

Sob um prisma solidarista, posto o custo humano da ausência da proteção aqui sustentada, recheado de valores não patrimoniais, a garantia de um patrimônio mínimo a todos está na constitucionalização do Direito Civil, juntamente com os demais institutos civilistas, caminhando rumo à repersonalização, devido à despatrimonialização operada pela Constituição Federal (base dos princípios fundamentais do atual ordenamento jurídico brasileiro). ${ }^{22}$

O formalismo da lei - entenda-se como a objetiva fixação da pessoa com deficiência como incapaz - deverá ser relevado, por decisão coerente e fundamentada, em nome da justiça do caso concreto, ${ }^{23}$ que permita a realização do ânimo constitucional de construir uma sociedade justa e solidária, com a proteção da pessoa com deficiência. Este ânimo, para longe de dúvidas, foi corporizado na Convenção de Nova lorque e na Lei Brasileira de Inclusão.

A ideia de reflexão do Direito a partir de problemas pode ser objeto de edificante estudo quando trata do que pode-se denominar de "lógica do razoável", ou seja, na concretude da situação jurídica é que localizar-se-ão as razões e os limites da aplicação do Direito. Nessa medida, se necessário for, por não acontecer um ajuste da proteção das pessoas com deficiência em semelhança aos incapazes, aludido alcance protetivo se dará por uma aplicação direta e pontual aos casos concretos em debate, especialmente na análise das partes envolvidas no

\footnotetext{
${ }^{22}$ FACHIN, Luiz Edson. Estatuto jurídico do patrimônio mínimo. 2.ed. atual. Rio de Janeiro: Renovar, 2006. p. 249.

23 Paulo Nalin, a esse respeito, deixa relevante lição: "O apelo ao pensamento tópico, imposto pelo cânone da solidariedade, não pode ser desprezado pelo juiz, escapando dos limites contratuais, especialmente na relação de adesão, em que a vontade contratual é fria e artificial. A solidariedade há de ser posta em experiência, a cada momento da relação jurídica, da pré-contratação à pós-execução. Tal desenho pragmático da solidariedade remete o intérprete do Direito em geral, especialmente o juiz, ao relevante posto de personagem central na sua descrição, pois não será o legislador e, tampouco, o executor das leis, quem o fará." (NALIN, Paulo. Do contrato: conceito pós-moderno. Em busca de sua formulação na perspectiva civil-constitucional. 2.ed. rev. e atual. Curitiba: Juruá, 2008. p.187).
} 
ISSN 1981-3694

(DOI): $10.5902 / 1981369432004$

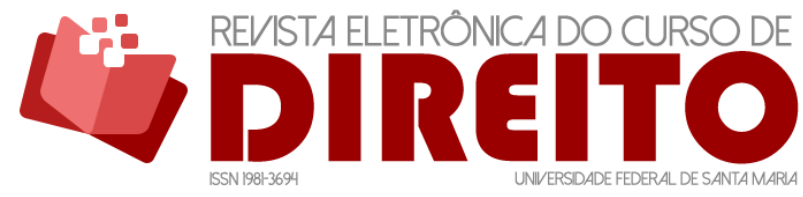

A INCONSTITUCIONALIDADE DA PROPOSTA DE RETORNO À INCAPACIDADE DA PESSOA COM DEFICIÊNCIA (PLS 757/2015) FRENTE À CONVENÇÃO DE NOVA IORQUE

eventual litígio, visando conhecer-se qual deles agiu, em relação ao outro, egoisticamente, infringindo o dever de respeito na situação específica.

A proteção, portanto, poderá ser da pessoa com deficiência ou do terceiro que eventualmente acumule prejuízo por com ele participar da relação jurídica. Eventual ação anulatória, como já se verificava no sistema jurídico anterior, deverá manter-se como mecanismo para anular (ou não) tratos jurídicos, para além da crença de que a segurança está na incapacidade.

Não se olvide da necessidade de se compreender o Direito Civil de hoje, com as lentes da Constituição, pela perspectiva da funcionalização. Funcionalizar os direitos da pessoa com deficiência é adequar sua proteção à nova tábua de garantias que a Carta Maior, a Convenção de Nova lorque e o Estatuto da Pessoa com Deficiência conferem. Descabido, a pretexto de proteção, retroceder-se a um sistema semelhante ao do Código Civil de 1916 - que pretendia defender a esfera patrimonial da sociedade em face dos “loucos de todo o gênero" - em desrespeito à regra internacional que o Brasil optou por compartilhar.

Por isso, mister compreender-se de uma vez por todas que é mais coerente localizar-se, no sistema jurídico, alternativas à incapacidade ao invés de a ela se retornar por meio de nova lei, que fora proposta, inclusive, antes mesmo da entrada em vigor do Estatuto. Se for para alterar legislação no que conforma à proteção de direitos, que se modifiquem, pontualmente, cada qual dos textos legais de benefícios que protegem os incapazes, adequando-os igualmente às pessoas com deficiência, tais como a não ocorrência da prescrição, a nulidade dos atos, entre outros.

\section{PAPEL DO INTÉRPRETE NA CONCRETIZAÇÃO DA CONVENÇÃO DE NOVA IORQUE E DO EPD}

A partir de tudo o que se viu, e como prelúdio de conclusão, é possível alcançar-se, agora, algum embrião de ideia para que seja possível atender-se, realisticamente, à demanda oriunda das realidades de vida das pessoas com deficiência, eu, como visto, são plenamente capazes e jamais poderão deixar de ser. Falar-se em retornar ao antigo art. $3^{\circ}$ e $4^{\circ}$ do Código Civil, com a prevalência das incapacidades é página virada, sem possibilidade de releitura. Qualquer edificação legislativa neste sentido será inconstitucional. 
ISSN 1981-3694

(DOI): $10.5902 / 1981369432004$

Não é necessária qualquer alteração legislativa apressada e mal pensada, uma vez que isso somente conduziria a algo generalizante, em sentido diverso da realidade de cada pessoa com deficiência. Como se sabe, são muitas as patologias (lato sensu) que conduzem a uma compreensão de deficiência e eventual inovação legislativa não as alcançará. Repita-se, qualquer ação com pretensão generalizante e pouco refletida poderá conduzir a algo inadequado. A transição que deve entrar em curso é de mentalidade, de consciência, de postura, reconhecendo-se que o Direito deve estar a "serviço da vida", como já se mencionou.

A alteração necessária, portanto, é de atitude, na coragem de promover-se a ruptura com a absoluta necessidade de uma subsunção legal, envidando-se esforços de decisão pela hermenêutica constitucional protetiva da pessoa com deficiência. Cabe ao intérprete conscientizar-se da necessidade de reconhecer na primazia da pessoa e na realidade propriamente dita que nela se faz sentir, os efeitos verdadeiros e as consequências das realidades que vivencia, na condição de deficiente.

A Academia tem construído fundamentos e condições para a consideração plena da pessoa com deficiência, mas devem também, a Advocacia e o Judiciário, agirem como verdadeiros intérpretes da Convenção, da Constituição e do EPD. Esses são os principais atores a quem é conferida a "mutabilidade real" de um sistema centenário e discriminador como o da incapacidade das pessoas. Faz-se mister, sim, trabalhar pelo reconhecimento e prestígio da capacidade, com coerência para atuar e decidir sobre peculiaridades de proteção das pessoas com deficiência, para além de simplesmente "carimbar" proteção somente pelo fundamento da incapacidade.

Ao advogado caberá o cuidado na compreensão inicial do caso concreto, da existência real de deficiência e dos prejuízos eventuais que tenham resultado a esta pessoa e a terceiros. Percebida a realidade, busca-se a proteção da multireferenciada legislação internacional e nacional, aplicando-a na proteção do deficiente e da sociedade.

O juiz, tendo em mãos aprofundadas teses das partes, mais facilmente conduzirá a decisão do caso concreto à mesma sintonia, qual seja, utilizar-se prioritariamente da axiologia constitucional e, aprofundando-se na concretude da situação deduzida em juízo, eleger a melhor decisão, em modulação diversa da tradicional lição estrutural e rigidamente conceitual que parte da premissa de incapacidade.

Um dos básicos fundamentos disso está na promoção da liberdade coexistencial, ou seja, a necessidade de integração existencial entre as pessoas na sociedade, mas que não 
necessariamente vá proteger o grupo, podendo, na perspectiva do caso concreto, preferir o individual ao coletivo.

A complexidade da vida, a pluralidade das formas de visão sobre o mundo e a diversidade recomendam a fuga da linearidade de decisões, a partir de contextos predeterminados e abstratos, como a da incapacidade. É essa liberdade plural que se quer colocar como função do direito civil, na esfera das potencialidades das pessoas com deficiência e daquelas sem deficiência, para cumprir-se a axiologia constitucional.

Não é demais repetir que o paradigma da incapacidade faz com que o jurista de formação clássica tenha dificuldade de pensar o Direito fora da "segurança" que o silogismo legalista proporciona. Mas se faz imperioso o transitar dos modos de operação do Direito, sob pena de o intérprete não acompanhar as condições de seu tempo. A atuação do julgador, do intérprete, nesse contexto, não deve residir tão somente no conteúdo específico da lei e da sua interpretação a partir dos paradigmas consagrados na clássica visão da civilística. ${ }^{24}$ A centenária figura da incapacidade, aos poucos, vai ficando para trás. Não é de se assustar se em breve até mesmo os menores de 18 anos sejam considerados plenamente capazes. Há interessantes pesquisas em andamento sobre o tema.

Como a construção do Direito se dá gradativa e dialeticamente, necessário que se busque uma hermenêutica critica, que conceba no Direito a complexidade da vida, interpretando-o a partir de seus princípios e valores fundamentais. Na consideração das pessoas com deficiência, sua proteção não pode ser tão somente adstrita a formalidade de um artigo que proteja a incapacidade, mas alargada pela substancialidade do ser humano e de sua dignidade, que estão igualmente expressos no conjunto legislativo ora em estudo.

24 É a lição de Luiz Edson Fachin: Destarte, como a constituição do Direito se dá gradativa e dialeticamente, abarcando leis elaboradas em momentos historico-ideologicos bastante distintos, busca-se uma hermenêutica critica, que conceba no Direito a complexidade da vida, interpretando-o a partir de seus princípios e valores fundamentais; uma hermenêutica não adstrita a formalidade, mas alargada pela substancialidade do ser humano e de sua dignidade. Remarque-se: como a hermenêutica está para além do puro e simples interpretar, uma vez que transcende o que está escrito, compondo um colóquio dialético entre leitor e texto, premente se faz sua construção em uni sistema dialeticamente aberto, que submeta perenemente as normas aos preceitos constitucionais e a contraprova da realidade. [...] Tendo por pressuposto essas compreensões, verifica-se que a maior contribuição trazida ao Direito Civil contemporâneo por uma hermenêutica diferenciada pode ser a consciência crítica e dialética para com a realidade de uma hermenêutica que não e somente a interpretação do mundo, mas também a sua transformação pelo próprio sujeito que nele esta inserto." (FACHIN, Luiz Edson. Pressupostos hermenêuticos para o contemporâneo direito civil brasileiro: elementos para uma reflexão crítica. In: V Jornada de Direito Civil. [8-10 de novembro de 2011, Brasília]. Brasília: Conselho da Justiça Federal, Centro de Estudos Judiciários, 2012. p.47). 
$\mathrm{Na}$ análise do caso concreto, caberá ao julgador decidir em favor da pessoa com deficiência, inclusive aplicando-lhe as proteções concedidas aos incapazes, mesmo que eles não mais sejam, exatamente pelo fundamento de que a semântica da palavra capacidade não surgiu para prejudicar, mas para melhorar a proteção.

Não é nada razoável defender que não se pode estender à pessoa com deficiência as proteções antes conferidas aos incapazes, pelo simples fato de hoje serem capazes. A Convenção e o EPD permitem uma interpretação protetiva da aplicação, a partir da aplicação do art. $9^{\circ}$, que trata do atendimento prioritário. Pode-se construir, até mesmo, que essa perspectiva de prioridade não é apenas formal, ou seja, para acessar os serviços descritos nos incisos do art. $9^{\circ}$ antecipadamente, mas, também, ser considerado em seu melhor interesse. Inclusive porque, é necessário permitir proteções especiais para que a pessoa com deficiência possa ser considerada como igual perante a lei, ou seja, com a proteção, tornam-se iguais às pessoas sem deficiência.

A tarefa do julgador (do intérprete), repita-se, não é fácil, mas é a realidade que prevalecerá no trânsito em curso do direito novecentista para o contemporâneo. Na lição de Gustavo Tepedino, o magistrado deve se afastar de premissas mecânicas e abstratas, para se ater à realidade da vida, identificando a norma do caso concreto a partir da realidade sobre a qual incide, extraindo as peculiaridades indispensáveis a própria interpretação. ${ }^{25}$

A força normativa da constituição, aliada aos fatos propriamente ditos, indicam a realidade da pessoa em sua dimensão concreta, é será o que deverá nortear a decisão jurídica (e judicial), para além da letra específica da lei, em específico. Em outras palavras, é possível proteger a pessoa com deficiência com os mesmos direitos (como por exemplo o art. 198, I, CC) pois a palavra capaz ou incapaz por si, nada significa mais para essas pessoas, mas, tão somente, a proteção que merecem por sua condição pessoal de deficientes. Fica, a partir dos fundamentos considerados no todo do presente escrito, sem qualquer justificativa e, portanto, absolutamente refutado, o secular argumento da "segurança jurídica" somente para os incapazes e que as pessoas com deficiência capazes estão desprotegidas.

No contexto ora desenvolvido, fácil distinguir a análise do caso concreto do que poderia se denominar por "casuísmo", uma vez que este se dá quando o julgador concede aos fatos a sua

${ }^{25}$ A lição do professor: "Ao magistrado, sob esse ponto de vista, caberá, em atividade simultânea, qualificar o fato, interpretar a norma e aplicar o direito. Não se vale de premissas abstratas imaginadas pelo legislador, em operação silogística, neutra e mecânica, apartada da realidade da vida, identificando, ao contrário, a norma do caso concreto a partir da pujante realidade sobre a qual incide e da qual, ao mesmo tempo, extrai as peculiaridades indispensáveis a própria interpretação." (TEPEDINO, Gustavo. Dez anos de código civil e a abertura do olhar do civilista. V Jornada de Direito Civil. [8-10 de novembro de 2011, Brasília]. Brasília: Conselho da Justiça Federal, Centro de Estudos Judiciários, 2012. p. 39). 
visão própria de mundo, independentemente de fundamento constitucional sustentável. A prospectiva, aqui, é a de que os casos, por meio da função como liberdade(s), mereçam cuidadosa atenção, em decisões dotadas de coerente e exauriente justificação (fundamentação) constitucional, a partir de afazeres doutrinários sofisticados e de aprimorada jurisprudência.

A fundamentação há que ser condizente, pois deve exteriorizar de modo racional e transparente as razões da interpretação favorável ao deficiente. A disposição constitucional, de natureza estruturante, assim como a análise dos fatos e da lei, deve estar em absoluta vinculação com a realidade concreta.

Portanto, não se trata de casuísmo considerar cada caso concreto de cada pessoa com deficiência e aplicar-lhe as vantagens perceptíveis aos incapazes, uma vez que a situação poderá (e deverá) ser replicada em futuros casos idênticos, na perspectiva de precedente, atendendo a requisito exposto por Thomas Bustamante, sob a rubrica de princípio da Universalizabilidade. ${ }^{26}$ Essa é a proposta de uma hermenêutica fundamentada na dignidade da pessoa com deficiência, para muito além do historicismo discriminador, do legalismo e da abstração.

\section{CONCLUSÃO}

A Convenção sobre os Direitos da Pessoa com Deficiência e seu Protocolo Facultativo (Convenção de Nova lorque) e a Lei Brasileira de Inclusão (Estatuto da Pessoa com Deficiência) inauguraram no ordenamento jurídico brasileiro a condição de plena capacidade das pessoas com deficiência, para além da incapacidade absoluta e relativa descritas pelo Código Civil de 2002. 0 Projeto de Lei do Senado $n^{\circ} 757 / 2015$ pretende promover alterações nos mencionados avanços que permitem a autonomia das pessoas com deficiência, por meio da repristinação do exato teor do art. $3^{\circ}$ do Código Civil, trazendo novamente à voga, sob suposto intuito protetivo, a incapacidade dessas pessoas. Além deste dispositivo, muitos outros que prejudicam a perspectiva de igualdade poderão ser afetados.

Essa medida não é compatível com a nova teoria das incapacidades formulada pela legislação internacional, recepcionada pela Constituição Federal de 1988, motivo pelo qual é mais coerente manter-se a capacidade plena das pessoas com deficiência, promovendo-se

26 BUSTAMENTE, Thomas da Rosa de. Princípios, regras e conflitos normativos: uma nota sobre a superabilidade das regras jurídicas e as decisões contra legem. Direito, Estado e Sociedade, n.37, p.175, jul./dez. 2010. p.175 
ISSN 1981-3694

(DOI): $10.5902 / 1981369432004$

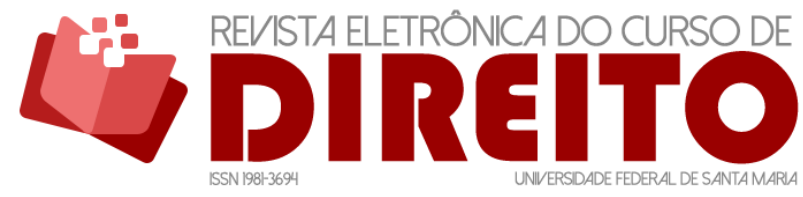

A INCONSTITUCIONALIDADE DA PROPOSTA DE RETORNO À INCAPACIDADE DA PESSOA COM DEFICIÊNCIA (PLS 757/2015) FRENTE À CONVENÇÃO DE NOVA IORQUE

ajustes outros na Lei Brasileira de Inclusão (EPD), compatibilizando-a com as disposições do Código Civil e do Código de Processo Civil de maneira a promover verdadeira autonomia e proteção.

No campo da atuação judicial, a hermenêutica a de prevalecer, tanto no aspecto constitucional, quanto na interpretação da norma infraconstitucional, é a do alargamento do âmbito de proteção dos incapazes, de modo a alcançar também as pessoas com deficiência, sem a necessidade de, para isso, retornar estas pessoas à condição de incapacidade. Da mesma maneira, a interdição, ressuscitada pelo Código de Processo Civil de 2015, deve ser excluída do sistema, convolando-se, como pretendeu o Estatuto da Pessoa com Deficiência, em ação de curatela.

Por fim, a presente pesquisa tem como intuito desafiar a reflexão acerca da necessidade de um amadurecimento sobre a compreensão do EPD, por ser um garantidor dos direitos fundamentais das pessoas com deficiência, que necessitam de um tratamento mais humano, solidário, com fomento de sua condição de iguais em relação aos demais, concedendo-se autonomia a estas pessoas, como pretendeu a Convenção de Nova lorque, ratificada pelo Brasil e que tem status de Constituição Federal.

\section{REFERÊNCIAS}

ARAÚJO, Luiz Alberto David; Ruzyk, Carlos Eduardo Pianovski. A perícia multidisciplinar no processo de curatela e o aparente conflito entre o estatuto da pessoa com deficiência e o código de processo civil: reflexões metodológicas à luz da teoria geral do direito. R. Dir. Gar. Fund., Vitória, v. 18, n. 1, p. 227-256, jan./abr. 2017.

BEVILÁQUA, Clovis. Codigo civil dos Estados Unidos do Brasil. São Paulo/Belo Horizonte: Livraria Francisco Alves, 1921. v. 1.

BRASIL. Constituição Federal Diário Oficial da União. Brasília: Senado Federal, 5 out. 1988. Disponível em: <http://www.planalto.gov.br/ccivil_03/Constituicao/Constituiçao.htm>. Acesso em: 01 dez. 2018.

BRASIL. Lei 10.406, de 10 de janeiro de 2002. Institui o Código Civil. Diário Oficial da União. Brasília: 10 jan. 2002. Disponível em: <

https://www.planalto.gov.br/ccivil_03/LEIS/2002/L10406compilada.htm>. Acesso em: 01 dez. 2018.

BRASIL. Lei 3.071, de $1^{\circ}$ de janeiro de 1916. Código Civil dos Estados Unidos do Brasil. Diário Oficial da União. Rio de Janeiro: 5 jan. 1916. Disponível em: < https://www.planalto.gov.br/ccivil_03/Leis/L3071.htm>. Acesso em: 01 dez 2018. 
BRASIL. Senado Federal. Projeto de Lei do Senado 757/2015. Altera a Lei $n^{\circ} 10.406$, de 10 de janeiro de 2002 (Código Civil), a Lei n 13.146, de 6 de julho de 2015 (Estatuto da Pessoa com Deficiência), e a Lei n 13.105, de 16 de março de 2015 (Código de Processo Civil), para dispor sobre a igualdade civil e o apoio às pessoas sem pleno discernimento ou que não puderem exprimir sua vontade, os limites da curatela, os efeitos e o procedimento da tomada de decisão apoiada. Disponível em: <

https://www25.senado.leg.br/web/atividade/materias/-/materia/124251 >. Acesso em: $07 \mathrm{dez}$. 2018.

BUSTAMENTE, Thomas da Rosa de. Princípios, regras e conflitos normativos: uma nota sobre a superabilidade das regras jurídicas e as decisões contra legem. Direito, Estado e Sociedade, n.37, p.175, jul./dez. 2010.

FACHIN, Luiz Edson. Estatuto jurídico do patrimônio mínimo. 2.ed. atual. Rio de Janeiro: Renovar, 2006.

FACHIN, Luiz Edson. Pressupostos hermenêuticos para o contemporâneo direito civil brasileiro: elementos para uma reflexão crítica. V Jornada de Direito Civil. [8-10 de novembro de 2011, Brasília]. Brasília: Conselho da Justiça Federal, Centro de Estudos Judiciários, 2012.

FRANÇA, Rubens Limongi. Instituições de Direito Civil. São Paulo: Saraiva, 1988, v. 1.

LÔBO, Paulo. Com avanços legais, pessoas com deficiência mental não são mais incapazes. CONJUR, 16 de agosto de 2015. Disponível em: <http://www.conjur.com.br/2015-ago16/processo-familiar-avancos-pessoas-deficiencia-mental-nao-sao-incapazes>. Acesso em 25 jul. 2016.

LÔBO, Paulo. Direito civil: parte geral. São Paulo: Saraiva, 2009.

NALIN, Paulo. Do contrato: conceito pós-moderno. Em busca de sua formulação na perspectiva civil-constitucional. 2.ed. rev. e atual. Curitiba: Juruá, 2008.

NEVARES, Ana Luiza Maia Nevares; SCHREIBER, Anderson. Do sujeito à pessoa: uma análise da incapacidade civil. In: TEPEDINO, Gustavo; TEIXEIRA, Ana Carolina Brochado; ALMEIDA, Vitor. [coords]. 0 direito civil ente o sujeito e a pessoa: estudos em homenagem ao professor Stefano Rodotà. Belo Horizonte: Editora Fórum, 2016.

SILVA, Alexandre Barbosa da. O Estatuto da Pessoa com Deficiência e o Regime das Incapacidades: Breve Ensaio sobre Algumas Possibilidades. In: EHRARDT JUNIOR, Marcos [coord]. Impactos do novo CPC e do EPD no direito civil brasileiro. Belo Horizonte: Editora Fórum, 2016.

SIMÃO, José Fernando. Estatuto da Pessoa com Deficiência causa perplexidade (Parte I). CONJUR, 06 de agosto de 2015. Disponível em: <http://www.conjur.com.br/2015-ago-06/josesimao-estatuto-pessoa-deficiencia-causa-perplexidade>. Acesso: 1 dez. 2018.

STRECK, Lênio Luiz. O fator stoic mujic, a juíza Kenarik e o papel dos advogados, hoje! CONJUR, 11 de fevereiro de 2016. Disponível em: <http://www.conjur.com.br/2016-fev- 
ISSN 1981-3694

(DOI): $10.5902 / 1981369432004$

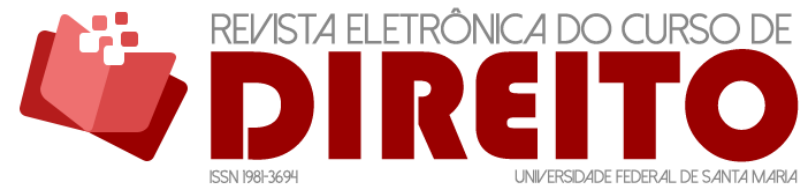

A INCONSTITUCIONALIDADE DA PROPOSTA DE RETORNO À INCAPACIDADE DA PESSOA COM DEFICIÊNCIA (PLS 757/2015)

FRENTE À CONVENÇÃO DE NOVA IORQUE

AlfRedo CopetTi Neto ALEXANDRE BARBOSA DA SILVA

11/senso-incomum-fator-stoic-mujic-juiza-kenarik-papel-advogados-hoje>. Acesso em 26 jul. 2016.

STRECK, Lênio Luiz. Verdade e consenso: constituição, hermenêutica e teorias discursivas. 4. ed. São Paulo: Saraiva, 2011.

TEPEDINO, Gustavo. Dez anos de código civil e a abertura do olhar do civilista. V Jornada de Direito Civil. [8-10 de novembro de 2011, Brasília]. Brasília: Conselho da Justiça Federal, Centro de Estudos Judiciários, 2012.

Recebido em: 03.04.2018 / Aprovado em: 21.10.2018 / Publicado em: 18.12.2018

COMO FAZER A REFERÊNCIA DO ARTIGO (ABNT):

COPETTI NETO, Alfredo; BARBOSA, Alexandre. A inconstitucionalidade da proposta de retorno à incapacidade da pessoa com deficiência (pls 757/2015) frente à convenção de Nova lorque. Revista Eletrônica do Curso de Direito da UFSM, Santa Maria, RS, v. 13, n. 3, p. 970-994, dez. 2018. ISSN 1981-3694. Disponível em: <

https: //periodicos.ufsm.br/revistadireito/article/view/32004 >. Acesso em: dia mês. ano. doi: http://dx.doi.org/10.5902/1981369432004. 